\title{
The Influence of Parameters of Ink-Jet Printing on Photoluminescence Properties of Nanophotonic Labels Based on Ag Nanoparticles for Smart Packaging
}

\author{
Olha Hrytsenko, ${ }^{1}$ Dmytro Hrytsenko, ${ }^{1}$ Vitaliy Shvalagin, ${ }^{2}$ Galyna Grodziuk, ${ }^{2,3}$ \\ and Nataliia Andriushyna ${ }^{2,3}$ \\ ${ }^{1}$ Institute of Publishing and Printing, National Technical University of Ukraine "Igor Sikorsky Kyiv Polytechnic Institute", \\ 1/37 Yangel Str., Kyiv 03056, Ukraine \\ ${ }^{2}$ L.V. Pisarzhevskii Institute of the Physical Chemistry, The National Academy of Science of Ukraine, 31 Nauky Ave., \\ Kyiv 03028, Ukraine \\ ${ }^{3}$ Nanomedtekh Ltd., Kyiv, Ukraine
}

Correspondence should be addressed to Olha Hrytsenko; olhasarapulova@gmail.com

Received 20 March 2017; Revised 2 June 2017; Accepted 8 June 2017; Published 11 July 2017

Academic Editor: Oscar Perales-Pérez

Copyright (C) 2017 Olha Hrytsenko et al. This is an open access article distributed under the Creative Commons Attribution License, which permits unrestricted use, distribution, and reproduction in any medium, provided the original work is properly cited.

\begin{abstract}
Ag nanoparticles are perspective for the use in ink-jet printed smart packaging labels in order to protect a customer from counterfeit or inform them about the safety of consumption of a packaged product via changeable luminescence properties. It is determined that, to obtain printed images with the highest luminescence intensity, using the most technologically permissible concentration of fluorescent component in the ink composition and applying inks to papers with the lowest absorbance are recommended. The highest contrast of a tone fluorescent image can be obtained on papers with high degree of sizing. It is found that the use of papers with low optical brightness agent (OBA) content with a wide range of luminescence intensity allows obtaining the same visual legibility of a printed nanophotonic label. The increase in the relative area of raster elements of an image leads to nonlinear increase in luminescence intensity of printed images in long-wave area of visible spectrum, affecting the luminescence color of a printed label. For wide industrial production of printed nanophotonic labels for smart packaging, the created principles of reproduction of nanophotonic images applied onto paper materials by ink-jet printing technique using printing inks containing Ag nanoparticles should be taken into account.
\end{abstract}

\section{Introduction}

Smart packaging (including intelligent packaging as its subgroup) gains its popularity in the world packaging market due to its ability to track a packaged food state and/or storing conditions and inform a customer about them [1-3]. There is a variety of ways to provide such functionality for a food packaging to make it smart; one of them is to equip a packaging with an active label containing some substances that will react to changes in a packaged product composition [4-6]. This reaction to compounds that indicate a food product aging or spoilage should be registered in some way, for example, by electronics and other instruments, or visually [7]. The most convenient way for a customer to receive the response of a smart packaging to a product state is to observe an active label visually. Therefore, labels with changeable optical properties are perspective for the use in smart food packaging. Nanomaterials can be utilized as functional components for such labels [8-10], as some of them, so called nanophotonic substances, possess and can change their photoluminescence properties in presence of traces of spoiled food, for instance, zinc oxide $(\mathrm{ZnO})$ nanoparticles [11-13]. Another promising substance for labeling food packages can be silver (Ag) nanoparticles, which, as shown in [14-16], can have intense luminescence bands. The physical mechanism of the luminescence of metal nanoparticles is described in $[17,18]$ and is due to the fact that as the size of the nanoparticles decreases, the metal band structure can become intermittent and break 
down into discrete energy levels analogous to energy levels in molecules. At the same time, metal nanoclusters can interact with light through electronic transitions between energy levels, resulting in intense light absorption and emission.

It should be noted that the use of Ag nanoparticles in packages has several advantages over semiconductor luminescent nanoparticles and luminescent particles of other metals; namely, Ag nanoparticles can have higher quantum luminescence yields than $\mathrm{ZnO}$ [19-21], and they are nontoxic in contrast to CdS and CdSe. Colloidal Au nanoparticles are stable while utilized for nanophotonic applications related to light trapping [22], but Ag nanoparticles are significantly cheaper than $\mathrm{Au}$ nanoparticles. At the same time, Ag nanoparticles are quite stable when their surface is blocked by a polymer [20]. Ag nanoparticles are known to be used for molecular detection on paper-based materials. For instance, as reported in [23], $60 \mathrm{~nm}$ sized Ag nanoparticles can be efficiently utilized for molecular surface enhanced Raman spectroscopy (SERS) detection as an active optical component on cardboard-based substrates. Besides, applied to food packaging, nanophotonic labels containing Ag nanoparticles with photoluminescence properties can serve as security labels [4] to complicate forgery or confirm authenticity of a product.

Nanoparticles can be deposited onto packaging materials using printing techniques as a part of printing inks. In this way, their application is low-cost, fast, and convenient [11]. Ink-jet printing is one of printing techniques widely used in packaging industry, especially for finishing operations such as printing manufacture and expiration dates onto a food packaging. Its employment for production of smart packaging labels will not require any major investments for reequipment of an enterprise; in fact, the existing ink-jet marking equipment could be used for depositing nanophotonic labels onto a packaging material.

Evidently, the use of printing techniques for application of nanophotonic labels, based on $\mathrm{ZnO}$ or Ag or other nanoparticles, requires extensive research. There are some aspects of the use of $\mathrm{ZnO}$ nanoparticles as part of printing inks for screen printing [8]. However, there is no data about the use of Ag nanoparticles for printed smart packaging. Nevertheless, the influence of various technological factors on the optical properties of printed labels should be considered before their industrial application. This study is aimed at determination of the effect of process parameters of application of ink compositions containing Ag nanoparticles by ink-jet printing onto paper packaging materials on the luminescence properties of the obtained printed labels for smart packaging.

\section{Materials and Methods}

$\mathrm{AgNO}_{3}$ (99.9\%), $\alpha$-lipoic acid (99.9\%), sodium borohydride $\left(\mathrm{NaBH}_{4}, 99 \%\right)$, and polyvinylpyrrolidone (PVP) MW 40,000 were obtained from Sigma Aldrich.

The Ag nanoparticles (NPs) were synthesized following a modification of the method published by Adhikari and Banerjee [24]. $\alpha$-Lipoic acid $\left(6 \times 10^{-2} \mathrm{M}\right)$ and $8,2 \mathrm{ml}$ of demi water were placed into a $20 \mathrm{ml}$ flask. Subsequently, $6 \times$ $10^{-2} \mathrm{M}$ of sodium borohydride was added, and $\alpha$-Lipoic acid was reduced to dihydrolipoic acid (DHLA), forming a clear solution after $30 \mathrm{~min}$. A solution of $\mathrm{AgNO}_{3}$ in water was added to the DHLA solution while stirring. The flask was wrapped in aluminum foil to minimize the influence of light. A clear color change from dark brown to a bright orange after 4-5 h indicated completion of the reaction. The NPs were subsequently stored in the dark. Concentration of Ag NPs after synthesis was $6 \times 10^{-3} \mathrm{M}$. To increase the photoluminescence intensity of the prepared colloids of $\mathrm{Ag}$ nanoparticles, stabilized with DHAL, $0.2 \mathrm{wt} \%$ of polyvinylpyrrolidone with total molecular weight of 40,000 was added.

The degree of sizing of paper is usually defined by stroke technique: the standard ink is applied onto paper by drawing pens graded in a series of strokes of equal length $(75 \mathrm{~mm})$ and a width that is growing $(0.25 \mathrm{~mm}, 0.5 \mathrm{~mm}, 0,75 \mathrm{~mm}, 1.0 \mathrm{~mm}$, $1.25 \mathrm{~mm}$, etc.). The width of a final stroke that is not blurred on paper and does not pass through it expresses the degree of sizing of paper in $\mathrm{mm}$.

The printed images were obtained by application of the developed nanophotonic compositions onto paper substrates using ink-jet printing. In order to study the details of production of tone fluorescent printed images, samples of raster fields $2 \mathrm{~cm} \times 2 \mathrm{~cm}$ were printed using the following materials and equipment:

(1) Printing inks with Ag nanoparticles in the form of aqueous solutions. The ink-jet printing ink was created by diluting the synthesized colloidal solution of Ag nanoparticles with distilled water. The initial solution of Ag nanoparticles possesses the needed ink-jet printing ink viscosity for the stable printing process.

(2) Papers without optical brighteners (non-OBA papers), as most papers usually contain optical brightness agents (OBAs), whose own luminescence can interfere with luminescence of printed images. The papers are characterized by different sizing degree that is their absorbance ability.

(3) Ink-jet printer Epson Stylus SX 4300, with a resolution of $600 \mathrm{dpi}$.

A number of factors affect the luminescence characteristics of the obtained ink-jet images; in this study, the main factors were selected and varied as follows:

(1) Printing ink composition, concentration of Ag nanoparticles: $2 \times 10^{-3} \mathrm{M}, 4 \times 10^{-3} \mathrm{M}$, and $6 \times 10^{-3} \mathrm{M}$.

(2) Relative area of raster elements of raster fields (for the case of applying a fluorescent label that contains tone gradations): $20 \%, 40 \%, 60 \%, 80 \%$, and $100 \%$.

(3) Sizing degree of a substrate (in this case paper materials are used as substrates): relatively low, medium, and high.

Photoluminescence intensity and color were selected as the investigated parameters of photoluminescence of the obtained printed samples.

A spectrophotometer Analytik Jena Specord 210 was used for obtaining optical density spectra of the colloidal solutions. A luminescence spectrometer Perkin-Elmer LS55 was used for obtaining photoluminescence spectra of the 


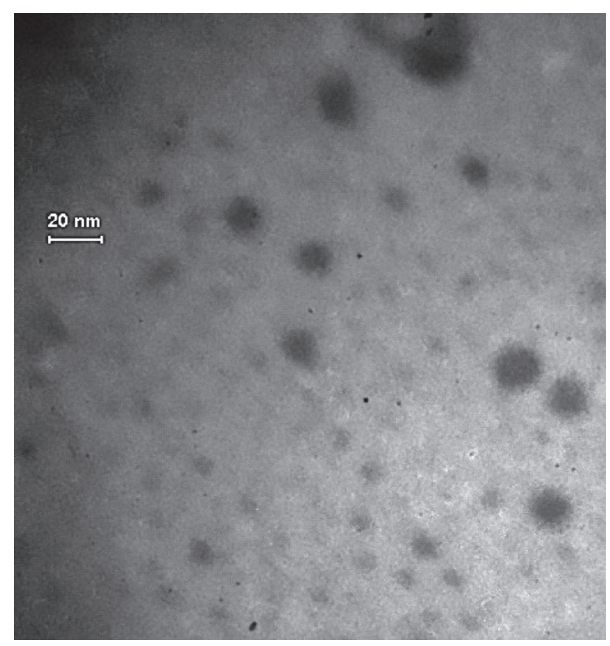

Figure 1: Transmission electron microscope image of colloidal solution of silver NPs stabilized DHLA acid with the addition of 0.2 mas. \% PVP of molecular weight $40,000 \mathrm{~g} / \mathrm{m} ;\left[\mathrm{Ag}^{0}\right]=6 \times 10^{-3} \mathrm{M}$.

colloidal solutions and printed samples with the $\lambda_{\text {exc }}=$ $435 \mathrm{~nm}$. Transmission electron microscopy (TEM) experiments were carried out on a Philips CM 20 FEG microscope at an accelerating voltage of $200 \mathrm{kV}$. The particle size distribution function measurement was carried out with a laser correlation spectrometer Zeta Sizer Nano S (Malvern, UK).

\section{Results and Discussion}

Ag NPs were synthesized by reducing silver nitrate with sodium borohydride using dihydrolipoic acid (DHLA) as a coordinating ligand. Initially, "large" Ag nanoparticles were formed, which were clearly visible in the TEM images (Figure 1).

During the synthesis, the larger Ag nanoparticles decrease in size, eventually forming luminescent $\mathrm{Ag}$ nanoclusters with an average size $2-3 \mathrm{~nm}$ [25]. The absorption spectrum in Figure 2 shows several sharp transition bands with maxima at 327,435 , and $497 \mathrm{~nm}$ combined with a shallow absorbance onset that starts around $700 \mathrm{~nm}$. The spectra obtained are similar to those presented in [24].

In contrast to the sharp absorbance features, Ag NPs exhibit a relatively broad deep red emission band (Figure 3 ) with a maximum at $\lambda=640 \mathrm{~nm}$ and a full width half maximum (FWHM) of $0.25 \mathrm{eV}$. This peak should emerge at luminescence spectra of the investigated papers after application of printing ink compositions onto their surfaces.

Size distribution of the fluorescent Ag nanoparticles was characterized by two techniques: transmission electron microscopy (TEM) and dynamic light scattering (DLS). TEM was used to visualize the shape as well as measure diameter of the inorganic Ag clusters. TEM image of the fluorescent Ag nanoclusters is presented in Figure 1. Initially, "large" Ag nanoparticles were formed, which were clearly visible in the TEM images (Figure 1). In the research [20] it was shown that, during the synthesis, the larger Ag nanoparticles decrease in

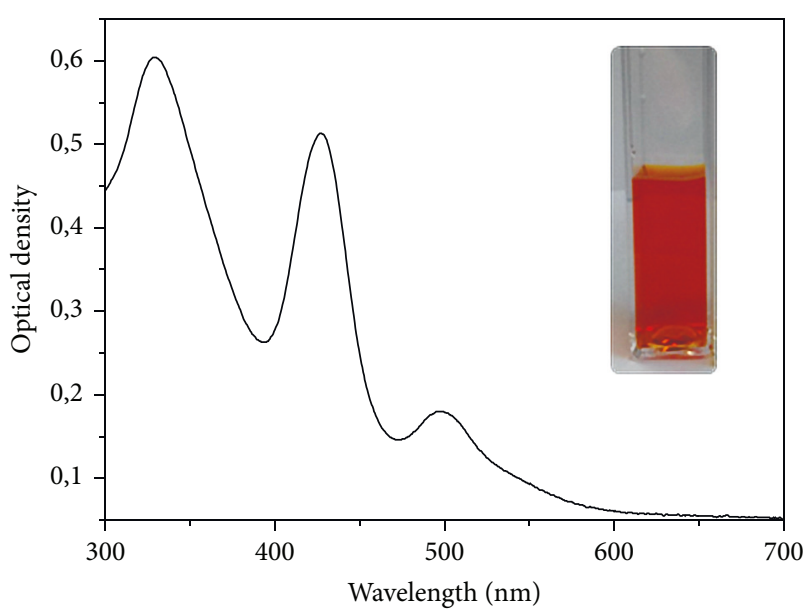

FIgURE 2: Absorption spectrum of Ag NPs stabilized with DHLA with the addition of 0.2 mas. $\%$ PVP dispersed in water; $\left[\mathrm{Ag}^{0}\right]=6 \times$ $10^{-3} \mathrm{M}$. (Inset: photographs of Ag nanoclusters in water under the exposure of daylight.)

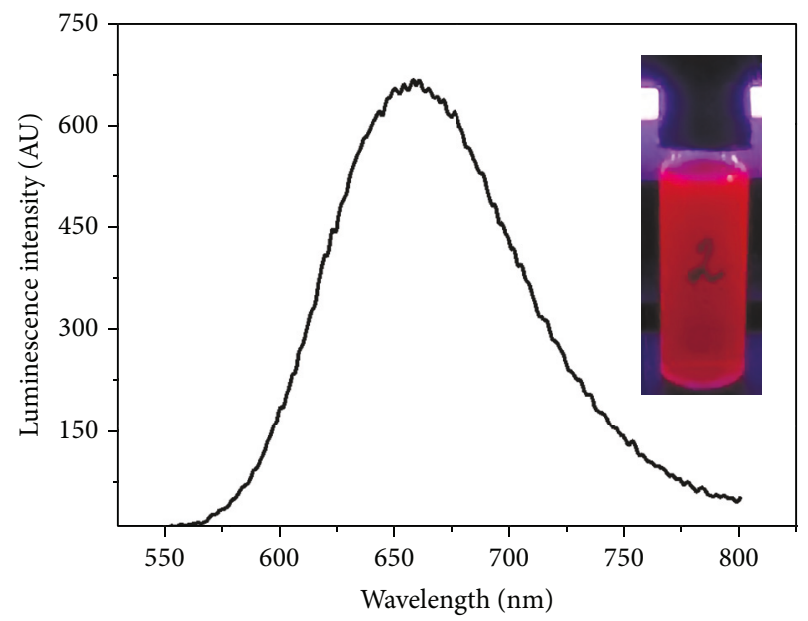

FIGURE 3: Fluorescence spectra $\left(\lambda_{\text {exc }}=435 \mathrm{~nm}\right)$ of Ag NPs stabilized with $\alpha$-DHLA with the addition of $0.2 \mathrm{wt} \%$ PVP dispersed in water. $\left[\mathrm{Ag}^{0}\right]=6 \times 10^{-3} \mathrm{M}$. Inset: photographs of fluorescent $\mathrm{Ag}$ nanoclusters in water under the exposure of UV light (excitation at $420 \mathrm{~nm})$.

size, eventually forming luminescent $\mathrm{Ag}$ nanoclusters after 3-5 h.

The size distribution obtained from DLS study (Figure 4) suggests that the population of $\mathrm{Ag}$ nanoclusters is not monodisperse. The wide size distribution of NPs correlates well with the wide emission band width. The observed average diameter of the NPs is $40 \mathrm{~nm}$.

The luminescence spectra of the selected papers are shown in Figure 5.

As shown in Figure 5, the selected papers are characterized by luminescence spectra with shoulder at $\lambda=510 \mathrm{~nm}$ and peak at $\lambda=580 \mathrm{~nm}$ and different luminescence intensity at $\lambda=460-650 \mathrm{~nm}$. Among the selected papers, paper G-1 has the lowest luminescence intensity, while paper I-8 has 


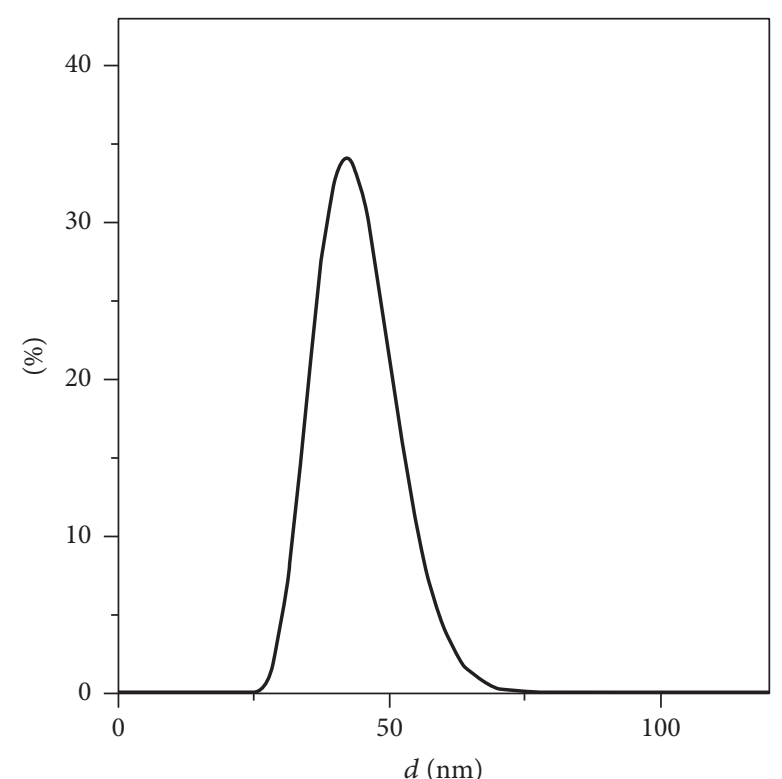

FIGURE 4: Hydrodynamic size distribution colloidal solution of silver NPs stabilized with DHLA with the addition of $0.2 \mathrm{wt} \%$ PVP with molecular weight $40,000 \mathrm{~g} / \mathrm{m} ;\left[\mathrm{Ag}^{0}\right]=6 \times 10^{-3} \mathrm{M}$.

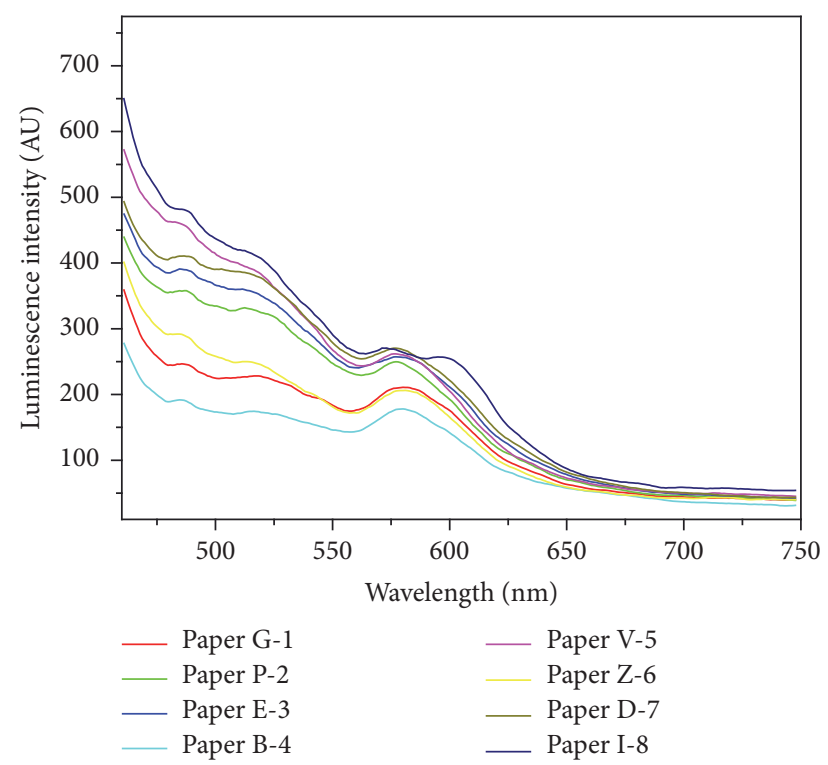

Figure 5: The luminescence spectra of the selected papers with low content of OBAs. $\lambda_{\text {exc }}=435 \mathrm{~nm}$.

the highest one. The luminescence spectrum of paper I-8 is slightly shifted to the long-wave zone.

Paper P-2 has the lowest absorbance and therefore the maximum degree of sizing, paper I-8 has somewhat lower degree of sizing, and paper E-3 and paper D-7 have the largest absorbance and, therefore, the lowest degree of sizing. The other selected papers are characterized by average absorbance and degree of sizing. Test results for degree of sizing of the selected papers are given in Table 1.
TABLE 1: The degree of sizing of the selected papers.

\begin{tabular}{lc}
\hline Paper & The degree of sizing, $\mathrm{mm}$ \\
\hline G-1 & 1.25 \\
P-2 & 2.00 \\
E-3 & 0.75 \\
B-4 & 1.00 \\
V-5 & 1.25 \\
Z-6 & 1.25 \\
D-7 & 0.75 \\
I-8 & 1.50 \\
\hline
\end{tabular}

Using the obtained colloidal solutions of silver nanoparticles, labels were printed on surface of papers with different degree of sizing. The luminescence spectra of these labels with different relative area of the raster elements are shown in Figure 6. As can be seen from Figure 6, as a result of applying ink compositions onto the paper, the form of luminescence spectrum of a printed image in general is undergoing the following changes comparing to the form of luminescence spectra of the paper: (1) a long-wave luminescence peak emerges at $\lambda=640 \mathrm{~nm}$, characteristic to the solution of $\mathrm{Ag}$ nanoparticles; (2) there are minor changes in the luminescence intensity at $\lambda=460-580 \mathrm{~nm}$.

Similar phenomena occur in all studied types of paper.

The dependencies of changes of own luminescence intensity of labels printed on different papers at $\lambda=640$ on different relative area of raster elements are presented in Figure 7. The own luminescence spectra of the printed samples were obtained to eliminate the optical influence of luminescence of paper substrates by subtracting the luminescence intensities of printed and unprinted areas at the studied paper substrates.

As can be seen from Figure 7, papers with the lowest absorbance and, therefore, the highest degree of sizing (paper P-2 and paper I-8) allow obtaining the highest luminescence intensity of the printed samples at $\lambda=640 \mathrm{~nm}$. It should be noted (see Figure 5) that paper P-2 has luminescence intensity lower than paper I-8, but luminescence intensity of the printed samples at $\lambda=640 \mathrm{~nm}$ on paper P-2 is, on the contrary, higher than that on paper I-8. These data indicate that there is no correlation between the intensity of luminescence of the initial paper materials and the luminescence of the labels printed on them based on silver nanoparticles.

At the same time, it was found that there is a strong correlation between the own luminescence intensity of labels printed with inks based on silver nanoparticles and the degree of sizing of paper (see Figure 8).

As shown in Figure 8, at the highest relative areas of raster elements of raster fields ( $80 \%$ and $100 \%)$, while increasing the degree of sizing of paper, there is a rapid increase in the own luminescence intensity of printed samples at $\lambda=640 \mathrm{~nm}$. At lower relative areas of raster elements of raster fields (20-60\%), there is some decrease in the own luminescence intensity of the printed samples at $\lambda=640 \mathrm{~nm}$ with the increase of the degree of sizing of paper. This means that the highest contrast of a tone fluorescent image (the difference 

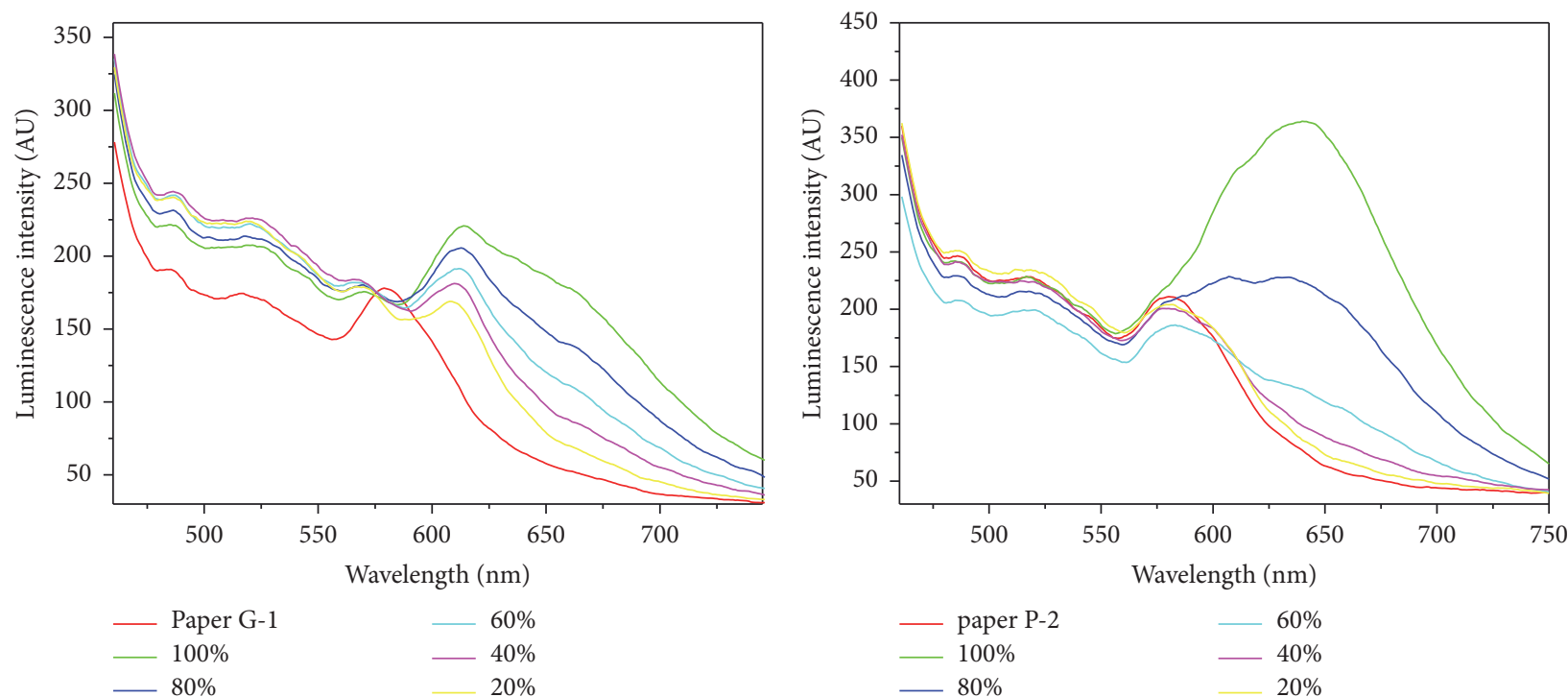

(a) Paper G-1
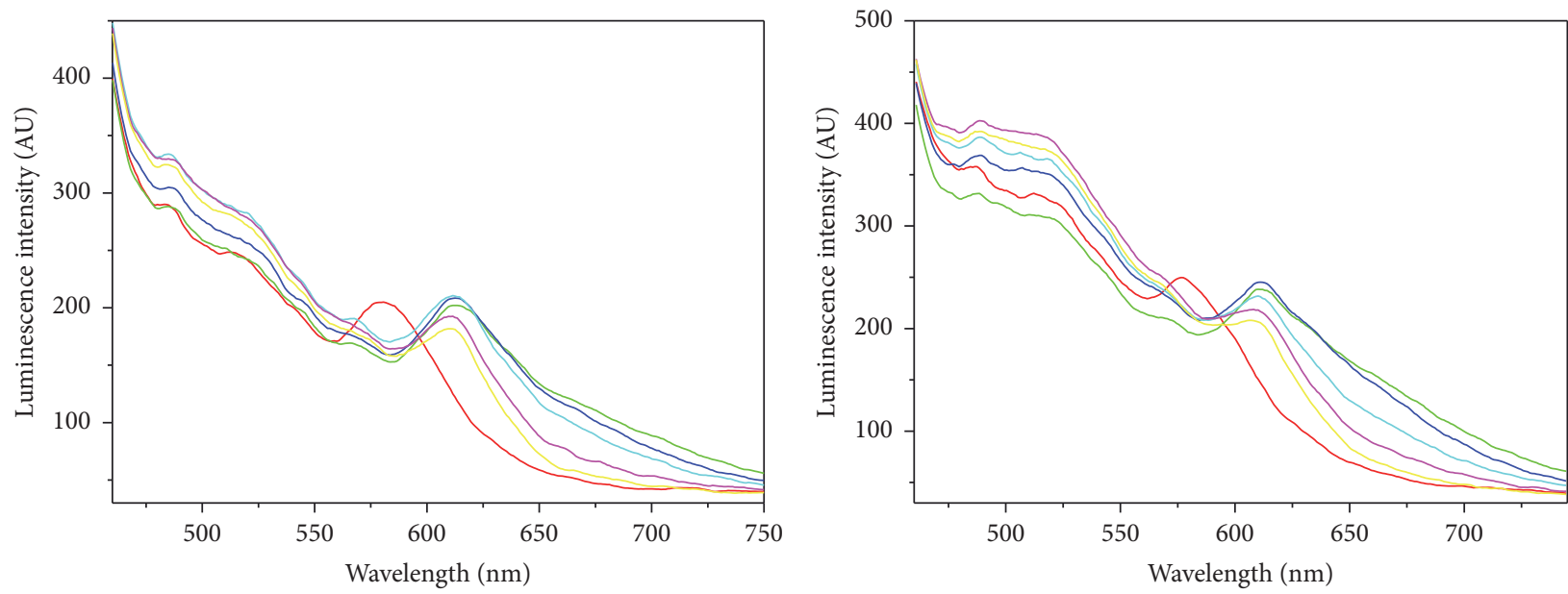

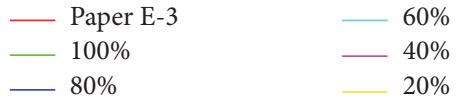

(c) Paper E-3

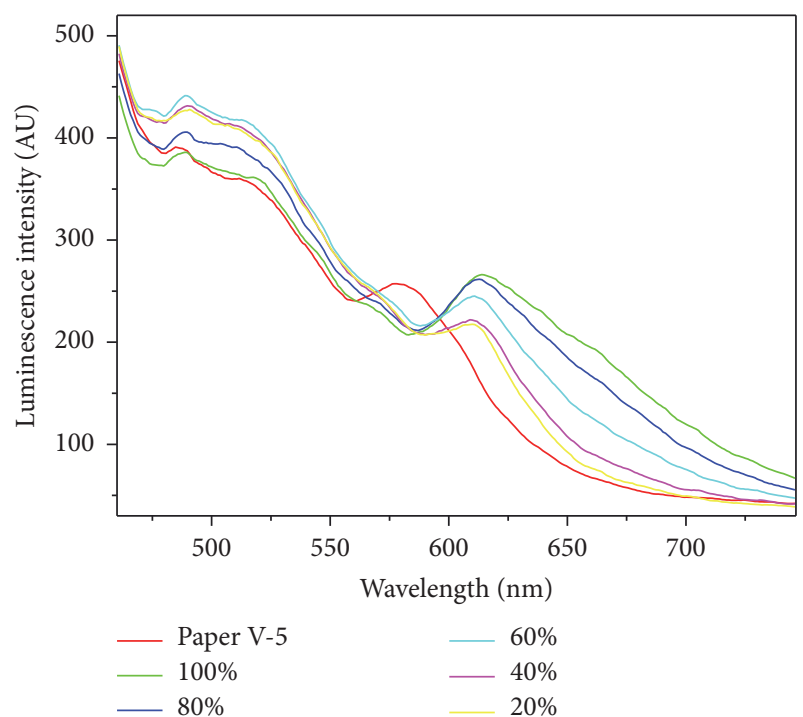

(e) Paper V-5

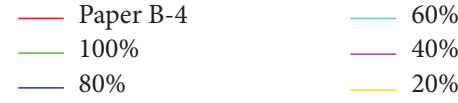

(d) Paper B-4
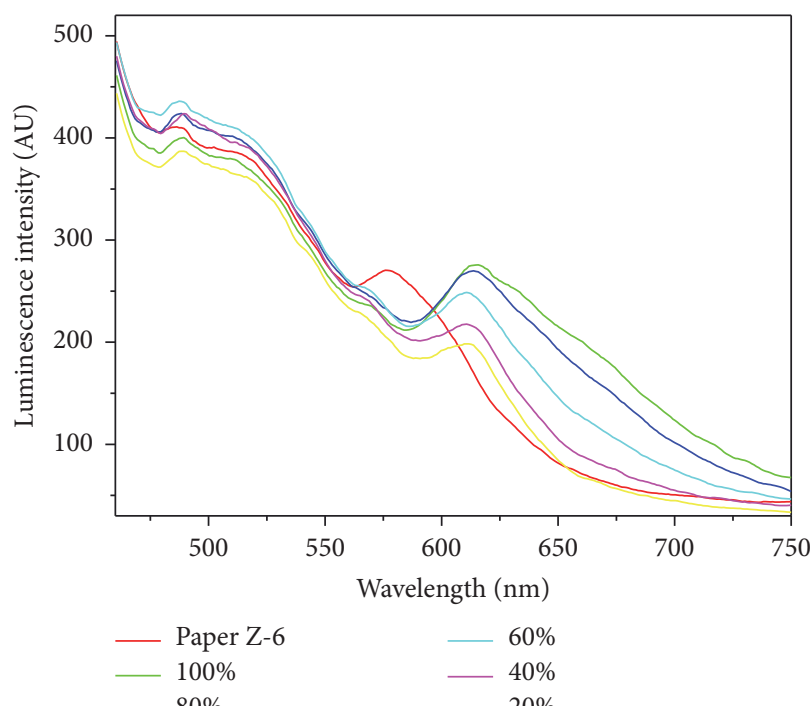

(f) Paper Z-6

FIgUre 6: Continued. 


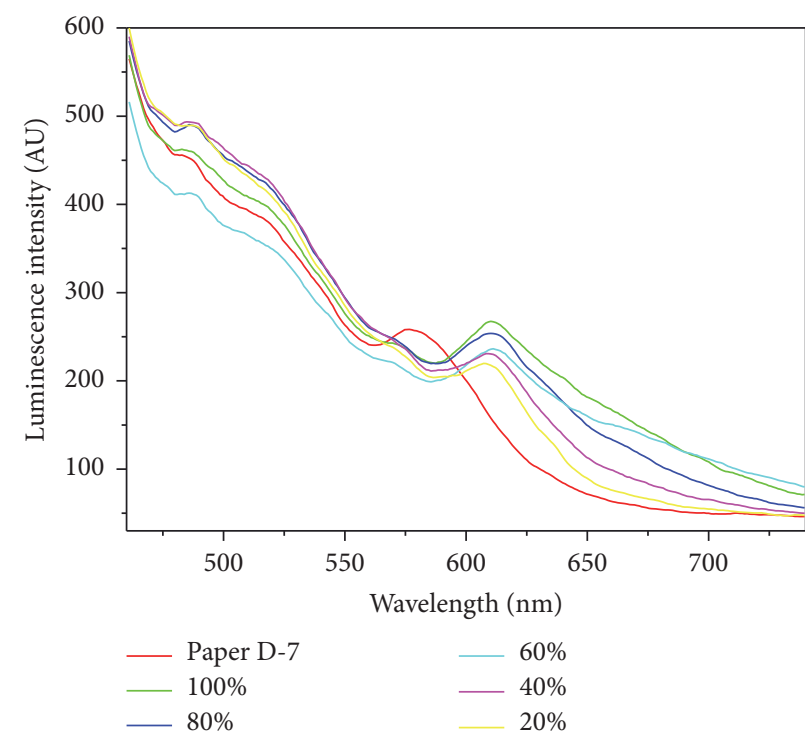

(g) Paper D-7

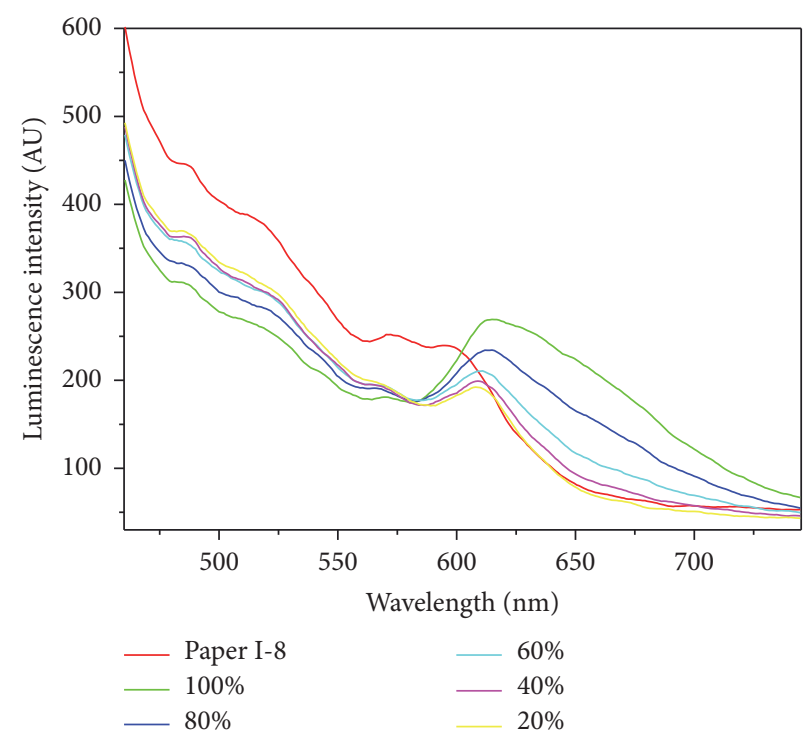

(h) Paper I-8

FIGURE 6: The luminescence spectra of samples printed on papers G-1, P-2, E-3, B-4, V-5, Z-6, D-7, and I-8 with nanophotonic ink composition for different relative area of raster elements of raster fields $(20-100 \%) \cdot\left[\mathrm{Ag}^{0}\right]=6 \times 10^{-3} \mathrm{M}$.

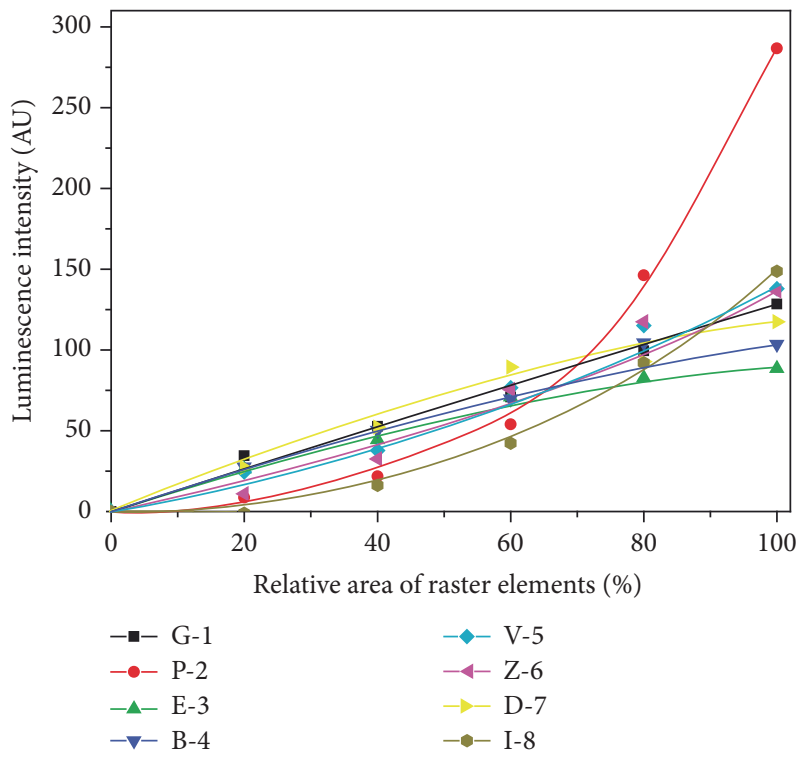

FIGURE 7: Changes of own luminescence intensity of printed samples with Ag nanoparticles at $\lambda=640 \mathrm{~nm}$ on different paper substrates (G-1, P-2, E-3, B-4, V-5, Z-6, D-7, and I-8) depending on relative area of raster elements of raster fields. $\left[\mathrm{Ag}^{0}\right]=6 \times 10^{-3} \mathrm{M}$.

between optical densities of the lightest and the darkest areas of a tone image) can be obtained on papers with high degree of sizing (1.5-2.0 $\mathrm{mm}$ and more).

The effect of the phosphor concentration in the ink on the own luminescence intensity of the printed labels was also investigated. The results are shown in Figure 9.

As can be seen from Figure 9, for almost all studied types of papers, there are line-shaped dependencies between the

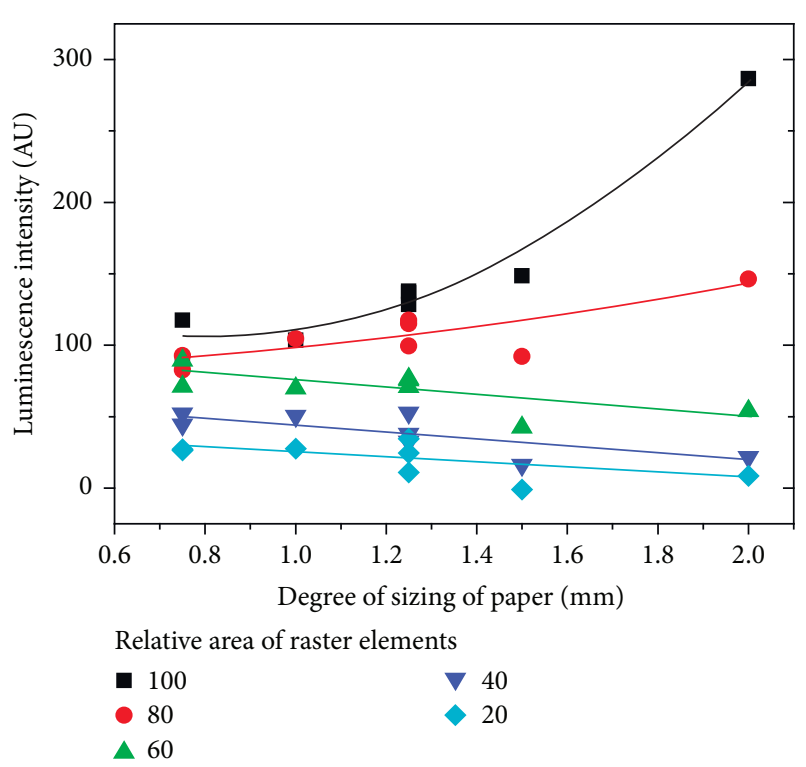

FIGURE 8: The dependence of the own luminescence intensity of the printed samples at $\lambda=640 \mathrm{~nm}$ on the degree of sizing of paper. The concentration of the fluorescent component in the ink composition is $\left[\mathrm{Ag}^{0}\right]=6 \times 10^{-3} \mathrm{M}$; the relative area of raster elements of raster fields varied from $20 \%$ to $100 \%$.

height of luminescence peak in the long-wave region of the visible spectrum (at $\lambda=640 \mathrm{~nm}$ ) and the concentration of the fluorescent component in the ink composition (a solution of Ag nanoparticles). Minor deviations from line-shaped dependencies are observed for papers G-1, B-4, Z-6, and I-8, which are most pronounced for the continuous printed areas (relative area of raster elements of raster fields is 100\%). Thus, the conclusion can be drawn that, regardless of the fluorescent 


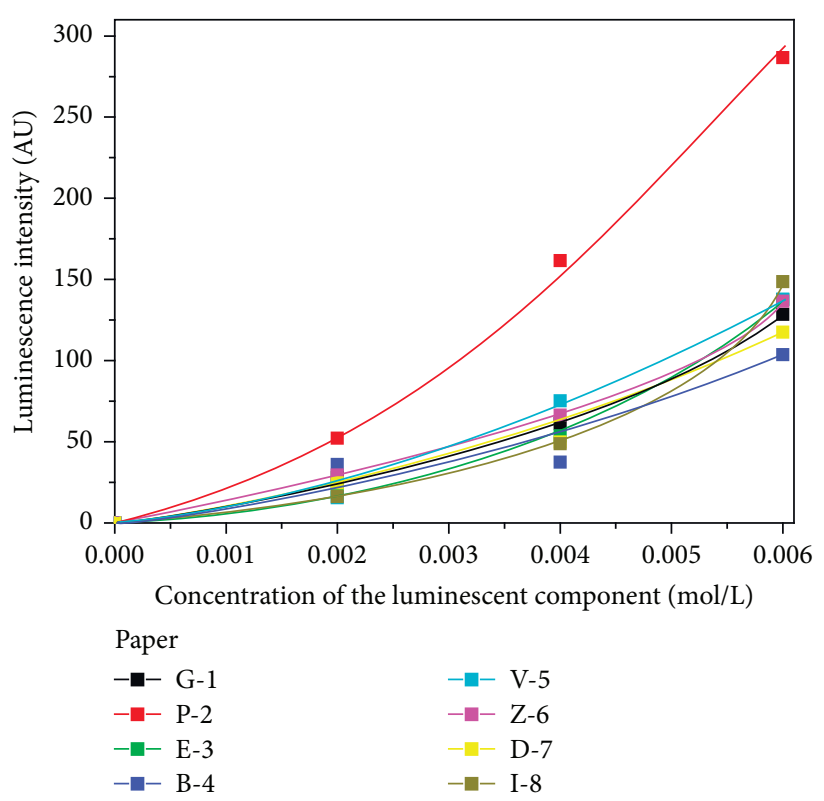

Figure 9: Changes of the own luminescence intensity of the printed samples with Ag nanoparticles at $\lambda=640 \mathrm{~nm}$ depending on the concentration of the phosphor on different paper substrates (G-1, P-2, E-3, B-4, V-5, Z-6, D-7, and I-8). Relative area of raster elements of raster fields is $100 \%$.
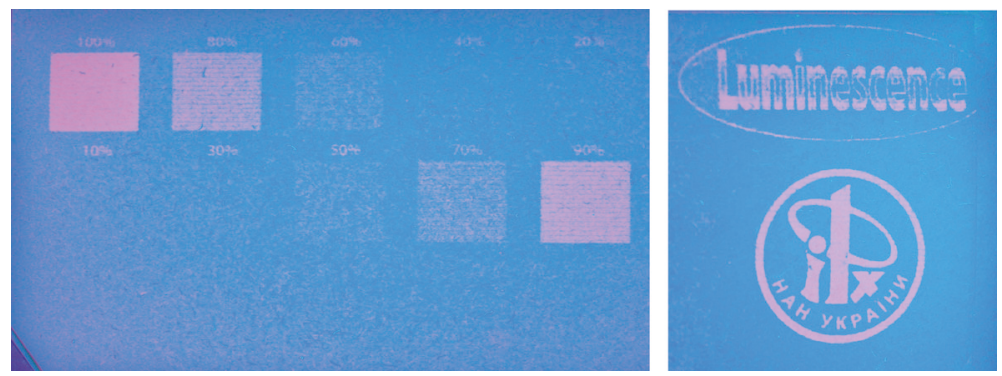

FIGURE 10: The photo of ink-jet printed samples under UV light on the selected paper (P-2) with low OBAs content.

properties of non-OBA paper, its absorbance, or degree of sizing, when the concentration of the fluorescent component (Ag nanoparticles) in the ink composition increases, there is a directly proportional increase in the luminescence intensity of printed images at $\lambda=640 \mathrm{~nm}$.

Thus, it was determined that when producing nanophotonic labels for smart packaging by ink-jet printing with printing inks containing Ag nanoparticles on paper materials, the following influence of technological factors on photoluminescence properties of the printed images should be taken into account:

(1) Regardless of the fluorescent properties of paper, its absorbance, and degree of sizing, when the concentration of the fluorescent component (Ag nanoparticles) in ink composition increases, there is a directly proportional increase in the luminescence intensity of a printed image at $\lambda=640 \mathrm{~nm}$.

(2) Printed samples possess the highest own luminescence intensity at $\lambda=640 \mathrm{~nm}$ when the nanophotonic ink compositions are deposited onto papers with the lowest absorbance and the highest degree of sizing (paper P-2 and paper I-8).

(3) The own luminescence intensity of printed samples does not practically depend on the luminescence intensity of a non-OBA paper as a substrate.

(4) The luminescence intensity of a printed image in a long-wave area of visible spectrum increases with the increase of relative area of raster elements of raster fields. The most rapid increase is observed when the concentration of the fluorescent component (Ag nanoparticles) in the ink composition is the highest and when an image is printed on papers with the highest luminescence intensity and the lowest absorbance (the highest degree of sizing).

Figure 10 shows the photo of ink-jet printed impressions obtained using the developed ink compositions containing 
Ag nanoparticles under ultraviolet (UV) light $(\lambda=350-$ $380 \mathrm{~nm}$ ) on the selected paper (P-2).

\section{Conclusions}

In this article, the principles of reproduction of nanophotonic labels applied to paper materials by ink-jet printing technique using printing inks containing Ag nanoparticles, for smart packaging, are investigated. The process of formation of a luminescent image on paper materials by ink-jet printing is studied. It is determined that, in order to obtain printed images with the highest luminescence intensity, using the most technologically permissible concentration of fluorescent component (Ag nanoparticles) in the ink composition is recommended. To obtain printed images with the highest luminescence intensity when reproducing dark tone gradations of an image, using papers with the lowest absorbance (therefore, with the highest degree of sizing) is recommended. Besides, the highest contrast of a tone fluorescent image (the difference between optical densities of the lightest and the darkest areas of a tone image) can be obtained on papers with high degree of sizing (1.5-2.0 $\mathrm{mm}$ and more). It is found that the use of papers with low OBAs content with a wide range of luminescence intensity is permissible, since luminescence intensity of a paper substrate practically does not affect the shape of luminescence spectrum of a printed image (i.e., luminescence color) but is only added to the luminescence of a printed image. It should be borne in mind that the visual legibility of a printed image at the same concentration of fluorescent component in the ink composition and the same relative area of raster elements of a raster field will be identical on papers with different luminescence of paper. It can be explained by the fact that fluorescent emission of a printed image is perceived by the eye of an observer in comparison to the fluorescent emission of paper. The comparison of the own luminescence intensities printed images shows that it does not depend on the luminescence intensity of paper as a substrate. It is determined that when reproducing gradations (transitions from light to dark areas) of a fluorescent label printed onto paper substrates, it should be taken into account that, firstly, the increase in the relative area of raster elements leads to practically no increase in the luminescence intensity of printed samples in medium area of visible spectrum (at $\lambda=$ $460-580 \mathrm{~nm}$ ); secondly, such increase in relative area leads to nonlinear increase in luminescence intensity of printed images in long-wave area of visible spectrum (at $\lambda=640 \mathrm{~nm}$ ), and on paper with the lowest absorbance (the highest degree of sizing) this increase is more significant. It affects the luminescence color of a printed label. The developed recommendations should be taken into account and enable the use of ink-jet printing inks containing silver nanoparticles for industrial production of nanophotonic labels for smart packaging.

\section{Conflicts of Interest}

The authors declare that there are no conflicts of interest regarding the publication of this paper.

\section{Acknowledgments}

This publication is based on the research provided by the grant support of the State Fund for Fundamental Research (Project N F64/10-2016 from 28.03.16).

\section{References}

[1] R. Ahvenainen and E. Hurme, "Active and smart packaging for meeting consumer demands for quality and safety," Food Additives and Contaminants, vol. 14, no. 6-7, pp. 753-763, 1997.

[2] K. L. Yam, P. T. Takhistov, and J. Miltz, "Intelligent packaging: concepts and applications," Journal of Food Science, vol. 70, no. 1, pp. 1-10, 2005.

[3] J. P. Kerry, M. N. O'Grady, and S. A. Hogan, "Past, current and potential utilisation of active and intelligent packaging systems for meat and muscle-based products: a review," Meat Science, vol. 74, no. 1, pp. 113-130, 2006.

[4] O. Sarapulova, V. Sherstiuk, V. Shvalagin, and A. Kukhta, "Photonics and nanophotonics and information and communication technologies in modern food packaging," Nanoscale Research Letters, vol. 10, article 229, 2015.

[5] B. Kuswandi, Y. Wicaksono, Jayus, A. Abdullah, L. Y. Heng, and M. Ahmad, "Smart packaging: sensors for monitoring of food quality and safety," Sensing and Instrumentation for Food Quality and Safety, vol. 5, no. 3-4, pp. 137-146, 2011.

[6] O. Sarapulova and V. Sherstiuk, "Nanophotonic, electro- and magnetoactive nanocomposites for printing and packaging," Molecular Crystals and Liquid Crystals, vol. 590, no. 1, pp. 1-10, 2014.

[7] C. E. Realini and B. Marcos, "Active and intelligent packaging systems for a modern society," Meat Science, vol. 98, no. 3, pp. 404-419, 2014.

[8] M. Avella, M. E. Errico, G. Gentile, and M. G. Volpe, "Nanocomposite sensors for food packaging," in Nanotechnological Basis for Advanced Sensors, NATO Science for Peace and Security Series B: Physics and Biophysics, pp. 501-510, Springer, Dordrecht, the Netherlands, 2011.

[9] U. K. Mishra, "Application of nanotechnology in food and dairy processing: an overview," Pakistan Journal of Food Sciences, vol. 22, no. 1, pp. 23-31, 2012.

[10] O. Sarapulova, V. Sherstiuk, and V. Shvalagin, "Luminescent nanosized composites for indicating and preventing compositional changes of packaged products in modern printed packaging," Nanoscience and Nanotechnology Letters, vol. 5, no. 11, pp. 1141-1146, 2013.

[11] O. O. Sarapulova and V. P. Sherstiuk, "Printed luminescent coverings based on nanosized $\mathrm{ZnO}$ for active and intelligent packaging," Functional Materials, vol. 21, no. 2, pp. 146-151, 2014.

[12] Z.-Y. Zhang and H.-M. Xiong, "Photoluminescent $\mathrm{ZnO}$ nanoparticles and their biological applications," Materials, vol. 8, no. 6, pp. 3101-3127, 2015.

[13] J. Y. Huang, X. Li, and W. Zhou, "Safety assessment of nanocomposite for food packaging application," Trends in Food Science \& Technology, vol. 45, no. 2, pp. 187-199, 2015.

[14] D. Gaspar, A. C. Pimentel, M. J. Mendes et al., "Ag and Sn nanoparticles to enhance the near-infrared absorbance of aSi:H thin films," Plasmonics, vol. 9, no. 5, pp. 1015-1023, 2014.

[15] I. Díez and R. H. A. Ras, "Fluorescent silver nanoclusters," Nanoscale, vol. 3, no. 5, pp. 1963-1970, 2011. 
[16] R. Li, C. Wang, F. Bo et al., "Microwave-assisted synthesis of fluorescent ag nanoclusters in aqueous solution," ChemPhysChem, vol. 13, no. 8, pp. 2097-2101, 2012.

[17] J. Zheng, P. R. Nicovich, and R. M. Dickson, "Highly fluorescent noble-metal quantum dots," Annual Review of Physical Chemistry, vol. 58, pp. 409-431, 2007.

[18] Y. Dai, X. Hu, C. Wang et al., "Fluorescent Ag nanoclusters in glass induced by an infrared femtosecond laser," Chemical Physics Letters, vol. 439, no. 1-3, pp. 81-84, 2007.

[19] H. Xu and K. S. Suslick, "Water-soluble fluorescent silver nanoclusters," Advanced Materials, vol. 22, no. 10, pp. 1078-1082, 2010.

[20] P. T. K. Chin, M. van der Linden, and E. J. van Harten, "Enhanced luminescence of Ag nanoclusters via surface modification," Nanotechnology, vol. 24, no. 7, Article ID 075703, 2013.

[21] D. J. Gargas, H. Gao, H. Wang, and P. Yang, "High quantum efficiency of band-edge emission from $\mathrm{ZnO}$ nanowires," Nano Letters, vol. 11, no. 9, pp. 3792-3796, 2011.

[22] M. J. Mendes, S. Morawiec, I. Crupi, F. Simone, and F. Priolo, "Colloidal self-assembled nanosphere arrays for plasmonenhanced light trapping in thin film silicon solar cells," Energy Procedia, vol. 44, pp. 184-191, 2014.

[23] A. Araújo, C. Caro, M. J. Mendes et al., "Highly efficient nanoplasmonic SERS on cardboard packaging substrates," Nanotechnology, vol. 25, no. 41, Article ID 415202, 2014.

[24] B. Adhikari and A. Banerjee, "Facile synthesis of water-soluble fluorescent silver nanoclusters and HgII sensing," Chemistry of Materials, vol. 22, no. 15, pp. 4364-4371, 2010.

[25] J. Zheng, Y. Ding, B. Tian, L. W. Zhong, and X. Zhuang, "Luminescent and raman active silver nanoparticles with polycrystalline structure," Journal of the American Chemical Society, vol. 130, no. 32, pp. 10472-10473, 2008. 

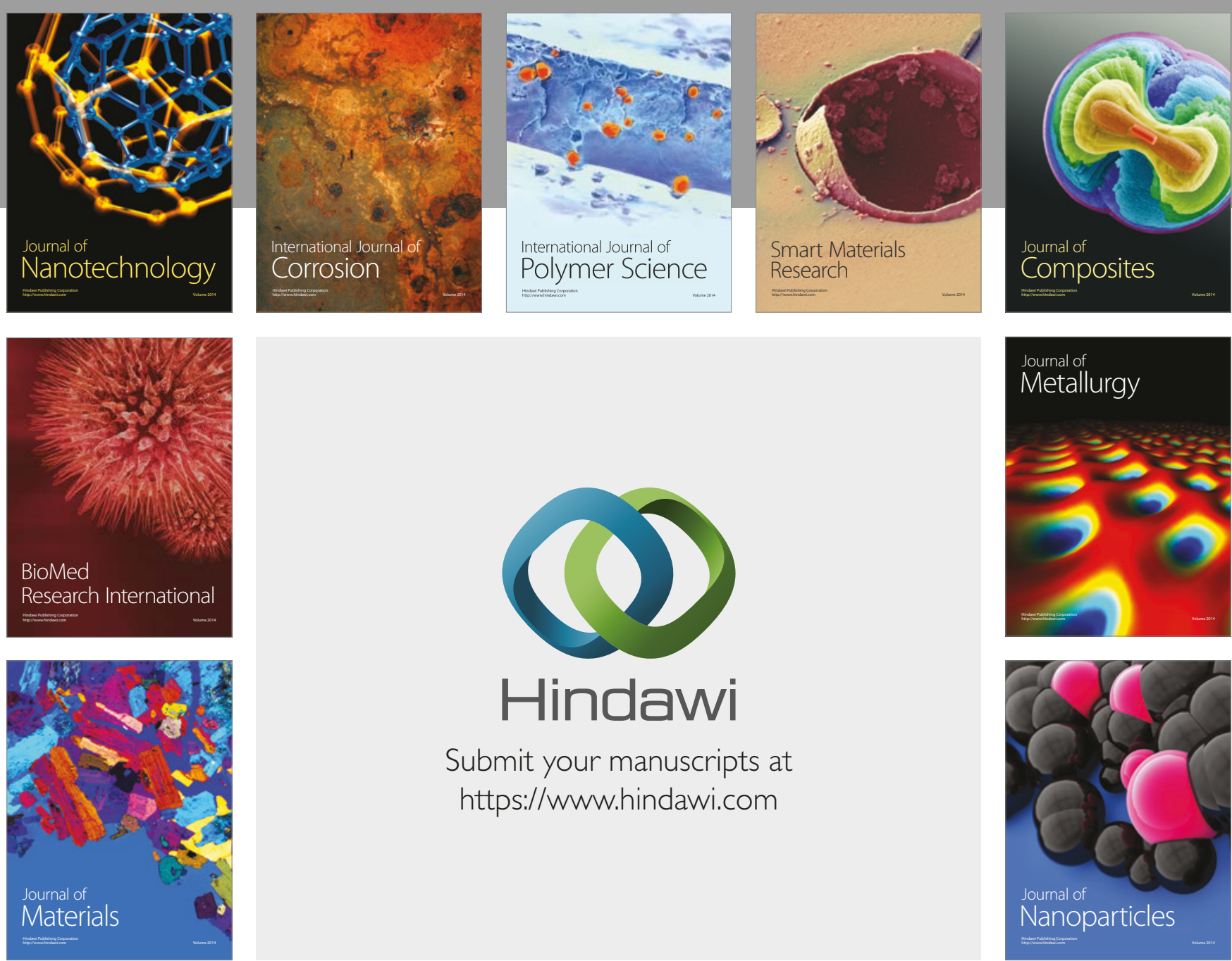

\section{Hindawi}

Submit your manuscripts at

https://www.hindawi.com
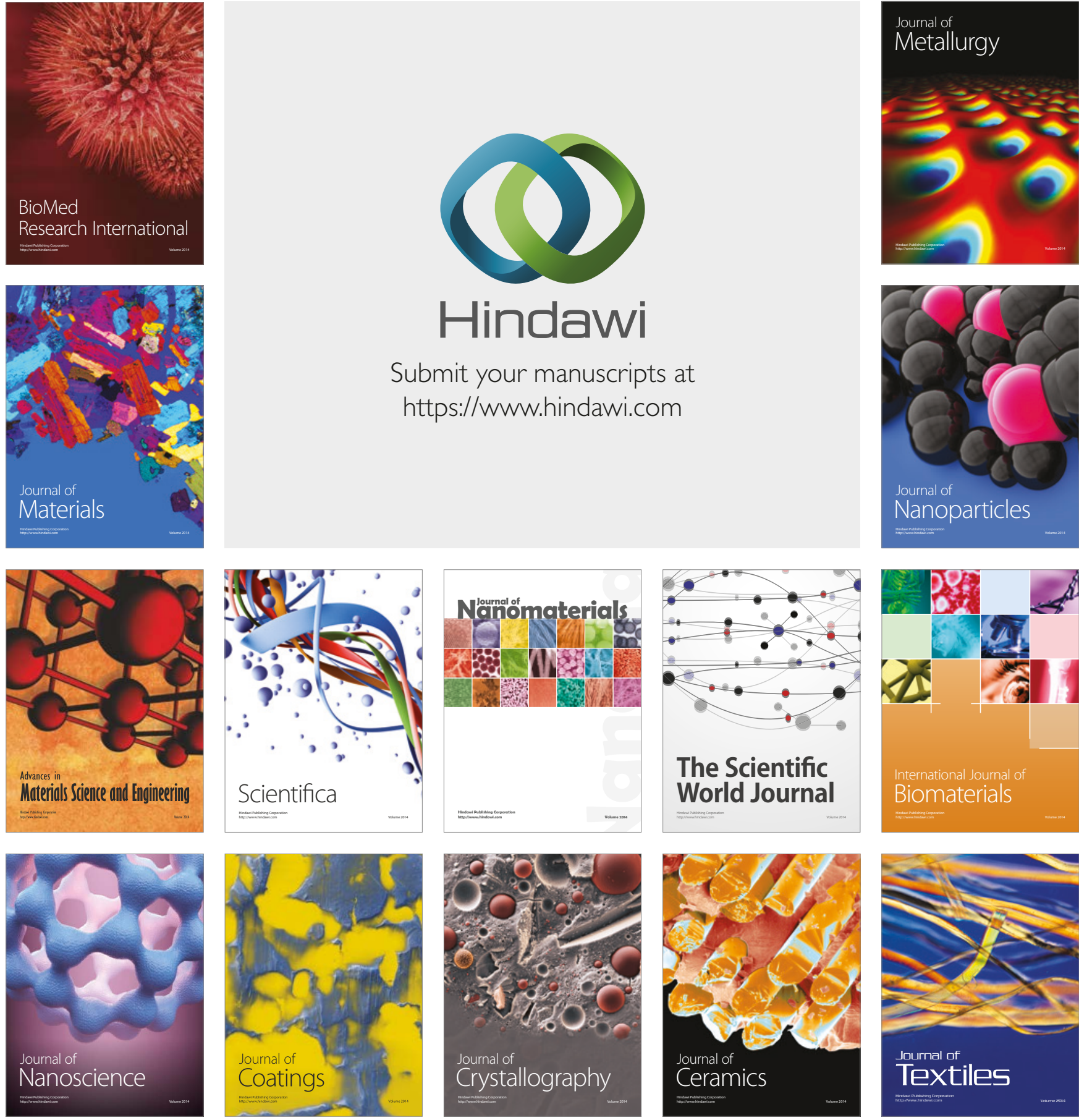

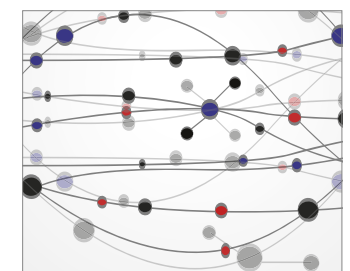

The Scientific World Journal
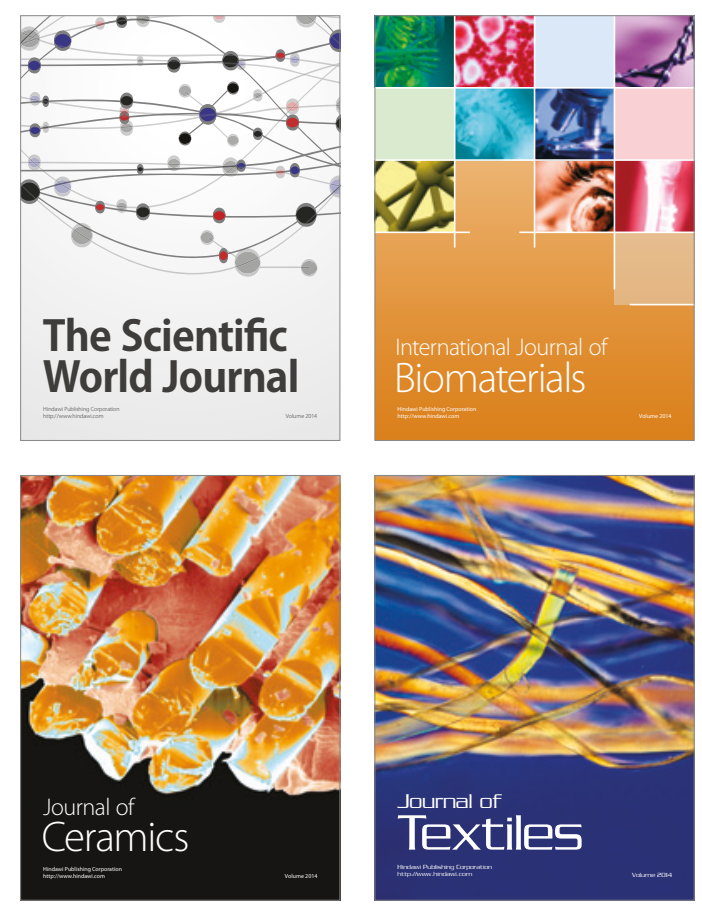